\title{
Charaeterizing Ground Motions That Collapse Steel Special Moment-Resisting Frames or Make Them Unrepairable
}

\author{
Anna H. Olsen, ${ }^{\text {a) }}$ M.EerI, Thomas H. Heaton, ${ }^{\text {b) }}$ M.EERI, and John F. Hall ${ }^{\text {b) }}$
}

This work applies 64,765 simulated seismic ground motions to four models each of 6- or 20-story, steel special moment-resisting frame buildings. We consider two vector intensity measures and categorize the building response as "collapsed," "unrepairable," or "repairable." We then propose regression models to predict the building responses from the intensity measures. The best models for "collapse" or "unrepairable" use peak ground displacement and velocity as intensity measures, and the best models predicting peak interstory drift ratio, given that the frame model is "repairable," use spectral acceleration and epsilon $(\varepsilon)$ as intensity measures. The more flexible frame is always more likely than the stiffer frame to "collapse" or be "unrepairable." A frame with fracture-prone welds is substantially more susceptible to "collapse" or "unrepairable" damage than the equivalent frame with sound welds. The 20-story frames with fractureprone welds are more vulnerable to P-delta instability and have a much higher probability of collapse than do any of the 6-story frames. [DOI: 10.1193/ 102612EQS318M]

\section{INTRODUCTION}

Welded steel moment-resisting frame buildings have been built in metropolitan areas with high seismicity since the early 1970s. Structural engineers have designed each building to withstand loading conditions prescribed by the relevant building code in force at the time of design and construction. Given adequate systems of construction and inspection, we can assume that an existing building will not fail catastrophically under the loads it was designed to withstand nor fail catastrophically under numerous other loads, which may be smaller or larger than the design loads. Because we are exclusively interested in seismic loads, this work addresses the question: What seismic excitations can a steel special moment frame (SMF) withstand or, pessimistically, what seismic excitations may induce failure in this class of building?

Academic and practicing engineers have studied this type of lateral force-resisting system. When SMFs failed to perform as expected in the 1994 Northridge earthquake, the engineering community established the causes of this failure. Their work - organized as the SAC Joint Venture - documented the state of SMF design and construction and made recommendations for improvements in both areas (see, e.g., Reis and Bonowitz 2000 for a list of relevant FEMA and SAC reports).

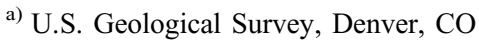

b) California Institute of Technology, Pasadena, CA
} 
Several research groups have simulated mid-rise (roughly 5- to 20-story) building responses to seismic ground motions. For example, Baker and Cornell (2005) proposed the use of spectral acceleration $\left(S_{a}\right)$ and epsilon $(\varepsilon)$ as a vector intensity measure. Epsilon measures the difference between observed $S_{a}$ and expected $S_{a}$ from a ground motion prediction equation (GMPE). The researchers applied 40 recorded ground motions, scaled to 13 intensity levels, to a reinforced concrete, moment-resisting frame model of an often studied building in Van Nuys, California, and to 15 generic frame models representing many structural systems. They found that the vector intensity measure $\left(S_{a}, \varepsilon\right)$ predicted the frame models' responses better than $S_{a}$ alone, and thus they recommended that $\varepsilon$ be included as a predictor of structural response or in the selection of ground motion records.

Jones and Zareian (2010) considered the performance of eight 6- or 20-story SMF models. Their study used: 18 large simulated ground motions from a M 7.15 earthquake on the Puente Hills Fault, 40 recorded ground motions scaled to represent the maximum considered earthquake ground motions for an area of downtown Los Angeles, and a further 40 records scaled to the conditional mean spectra of the considered buildings. The investigators compared the numbers of 6- or 20-story frame models that exceeded a peak interstory drift ratio of 0.06 , concluding that the 20 -story models were safer than the 6 -story models and, in particular, that the 20-story models were "less vulnerable" than the 6-story models to the problem of fracture-prone welds.

The purpose of this study is to characterize seismic ground motions that cause significant damage to existing mid-rise SMFs. Such a study could not be performed with recorded ground motions alone because there are so few records with sufficient energy content at long periods to induce SMF collapse. Ground motions with significant energy content at long periods are expected to result primarily from large-magnitude earthquakes. In the past decade, earth scientists have generated numerous seismic ground motions from simulations of fault rupture and wave propagation. We collect almost 65,000 simulated time histories from scenario crustal earthquakes in California, and we apply them to models of SMF buildings. The intensities of these ground motions range from quite small to extreme. By covering this complete range, we can characterize SMF building response from linear through nonlinear to highly nonlinear. We do not characterize the likelihood of these records; instead, we simply use them to characterize the intensities of ground motions that cause collapse or unrepairable damage.

By identifying and describing ground motions that significantly damage existing mid-rise SMFs, we also characterize the SMFs' seismic load-resisting capacity. There are many distinct building designs in the class of "existing mid-rise SMF," but in this study we do not attempt to fully represent this variety. Instead, we use building designs and models that allow one-to-one comparisons of a shorter mid-rise frame versus a taller mid-rise frame, or a stiffer and higher-strength frame versus a more flexible and lower-strength frame, or a frame with sound versus fracture-prone welds. The building models that we use capture higher and lower values of these important characteristics of existing mid-rise SMFs, but they are not representative of all buildings in this class.

After describing the ground motions and frame models used in this study, we compare four intensity measures - specifically, peak ground displacement (PGD), peak ground velocity (PGV), spectral acceleration, and epsilon - to determine which scalar or vector measure best predicts building response. We propose several alternative functional relationships 
between intensity measure and building response measure and determine which best characterizes this relationship. Thus, we also characterize the intensity of ground motions that cause failure of steel special moment-resisting frames or the intensities that cause a certain interstory drift ratio.

\section{GROUND MOTIONS AND BUILDING MODELS}

To establish a probabilistic relationship between ground motion intensity measures and the seismic response of existing SMFs, we collect a set of 64,765 simulated ground motions and use them in nonlinear time history analyses of eight SMF computational models. We characterize the frame model response as "collapse" or "standing" and as "repairable" or "unrepairable"; if "repairable," we calculate the peak interstory drift ratio (IDR). We characterize the seismic ground motions using PGD, PGV, $S_{a}$, and $\varepsilon$ either as scalar or vector intensity measures. The following sections detail this methodology.

\section{GROUND MOTIONS AND INTENSITY MEASURES}

We collect simulated ground motions from several scenarios of crustal earthquakes in California. Table 1 lists these scenarios with their important characteristics. The scenario magnitudes range from 6.3 to 7.8, and the faults are under the greater Los Angeles and San Francisco metropolitan areas. Note that the energy content of the simulated ground motions is either long period (greater than $2 \mathrm{~s}$ ) or broadband (greater than $0.1 \mathrm{~s}$ ). The listed references provide details on how the scenario earthquakes and resulting ground motions were generated.

We use four metrics to characterize each ground motion: PGD, PGV, $S_{a}$ at four periods, and $\varepsilon$. To calculate the PGD (or PGV) of a ground displacement (velocity) time history, we first find the vector amplitude (also known as the $L_{2}$ norm) of the two orthogonal horizontal components at each time step. A few simulated ground motions have a monotonically increasing or decreasing baseline. This feature is not physical, and in some cases the largest dynamic displacement is at the end of the record. To determine the maximum dynamic displacement that occurs earlier in the record, we find the largest vector amplitude over the time interval between the first seismic wave arrival and one-half of the remaining record length. Based on a visual check of many dozens of records, we believe that this algorithm eliminates

Table 1. Summary of scenario earthquakes from which the simulated ground motions were generated

\begin{tabular}{lcccrc}
\hline \hline Fault & Reference & Magnitude & $\begin{array}{c}\text { Energy } \\
\text { content }\end{array}$ & Sites $^{1}$ & Number $^{2}$ \\
\hline Loma Prieta & Aagaard et al. (2008b) & 6.9 & Long period & 4,945 & 2 \\
Northern San Andreas & Aagaard et al. (2008a) & 7.8 & Long period & 4,945 & 3 \\
Puente Hills & Graves and Somerville (2006) & 7.15 & Broadband & 648 & 5 \\
Various faults & Day et al. (2005) & $6.3-7.1$ & Long period & 1,600 & 23 \\
in the Los Angeles basin & & & & & \\
\hline \hline
\end{tabular}

${ }^{1}$ Number of ground motion sites for each scenario earthquake.

${ }^{2}$ Number of scenario earthquakes for each study. 
the effects of baseline drift and finds the PGD during strong shaking. The large number of simulated ground motions precludes checking all time histories. Note that the long-period PGD and PGV are likely found at the same time step in the ground motion, but the broadband PGD and PGV are not likely coincident at a time step. We denote PGDs and PGVs calculated from a long-period ground motion with the subscript $l p$ and those from a broadband ground motion with the subscript $b b$.

We calculate $S_{a}$ at the fundamental elastic period of each frame model (abbreviations are described in the next section): $1.16 \mathrm{~s}$ (J6), $1.54 \mathrm{~s}$ (U6), $3.04 \mathrm{~s}$ (J20), and $3.47 \mathrm{~s}$ (U20). The final intensity measure, $\varepsilon$, developed by Baker and Cornell (2005), measures the difference between an observed $\log _{e}\left(S_{a}\right)$ and the expected $\log _{e}\left(S_{a}\right)$ from a GMPE in units of standard deviation. We use the GMPE in Boore and Atkinson (2007, Equation 3.1) to define the expected $\log _{e}\left(S_{a}\right)$ for each simulated time history. Note that Boore and Atkinson estimated the parameter values of their GMPE using recorded ground motions from past earthquakes. By calculating $\varepsilon$ in the way just described, we are comparing the $S_{a}$ of a simulated ground motion to the expected $S_{a}$ based on past observations of seismic ground motions.

In the Introduction, we allude to our choice to use simulated, rather than recorded, seismic ground motions in this study. The wealth of simulated ground motions allows us to calculate SMF model responses over a wide range of intensity measure values. These frame model responses, however, would not provide insight into SMF behavior if the simulated ground motions were inconsistent with records or if a long-period ground motion induced a frame model response inconsistent with that caused by the equivalent ground motion with shortand long-period energy content. The studies listed in Table 1, which generated the ground motions used in this study, validated their models in part by comparing their simulation results against corresponding records. Using records from the 1999 Chi-Chi and 2003 Tokachi-Oki earthquakes, Krishnan et al. (2006) demonstrated that 13 records filtered to remove short periods induced interstory drifts in their two 18-story moment-resisting frames consistent with those caused by the unfiltered records. Thus, we believe that this study's findings would not change if tens of thousands of records were used in place of the simulated ground motions on the same range of intensity measure values. Also, the findings on moment-resisting frame behavior are consistent whether long-period or broadband ground motions are used.

Since recorded ground motions are broadband, we find a multiplicative factor for the interested reader to convert from a long-period PGV to a broadband PGV. This conversion is not implemented for any PGVs in this paper. We apply a fourth-order, low-pass Butterworth filter to all broadband ground motions and recalculate the PGV for these filtered time histories. The PGVs from the broadband ground motions, $P G V_{b b}$, can be regressed on the PGVs from the filtered ground motions, $P G V_{f}$, using a linear or quadratic relationship:

$$
P G V_{b b}=0.006715+1.473 \cdot P G V_{f}+\varepsilon_{\text {linear }}
$$

or

$$
P G V_{b b}=0.1163+1.167 \cdot P G V_{f}+0.1224 \cdot P G V_{f}^{2}+\varepsilon_{\text {quadratic }}
$$

where the error is assumed to be normally distributed with mean zero and standard deviation $0.2364 \mathrm{~m} / \mathrm{s}$ (linear) or $0.2211 \mathrm{~m} / \mathrm{s}$ (quadratic). (Inspection of the logarithm of the data 
indicates that long-period and broadband PGVs are not related through a power law.) Figure 1 shows the data and the linear and quadratic fits. At large PGV values the data clearly deviate from the line. Although we have no physical reason to expect a quadratic relationship between $P G V_{l p}$ and $P G V_{b b}$, we do expect to observe the largest PGVs in the near-source area of a fault, which is also where we expect to see ground motions with the largest highfrequency content. Based on our available data and interest in PGVs of $1-3 \mathrm{~m} / \mathrm{s}$, the linear equation provides an adequate conversion from long-period to broadband PGV: a broadband PGV is approximately 1.5 times a long-period PGV with a standard deviation of $0.24 \mathrm{~m} / \mathrm{s}$. The residuals of the linear fit are heteroscedastic in this range, so this relationship should be used only as a rough approximation.

\section{BUILDING MODELS AND RESPONSE METRICS}

We use eight models of SMFs developed by Hall (1997). The building height is either 6 or 20 stories, representing a shorter or taller mid-rise frame. For a given number of stories, the frame is either stiffer and higher strength or more flexible and lower strength. The lateral force-resisting system of the former satisfies the Japanese seismic building provisions of 1992 [with design base shear normalized by weight, $Q / W$, equal to 0.20 (6 stories) or 0.08 (20 stories)], and the lateral force-resisting system of the latter satisfies the 1994 Uniform Building Code seismic provisions [ $V / W$ equal to 0.04 (6 stories) or

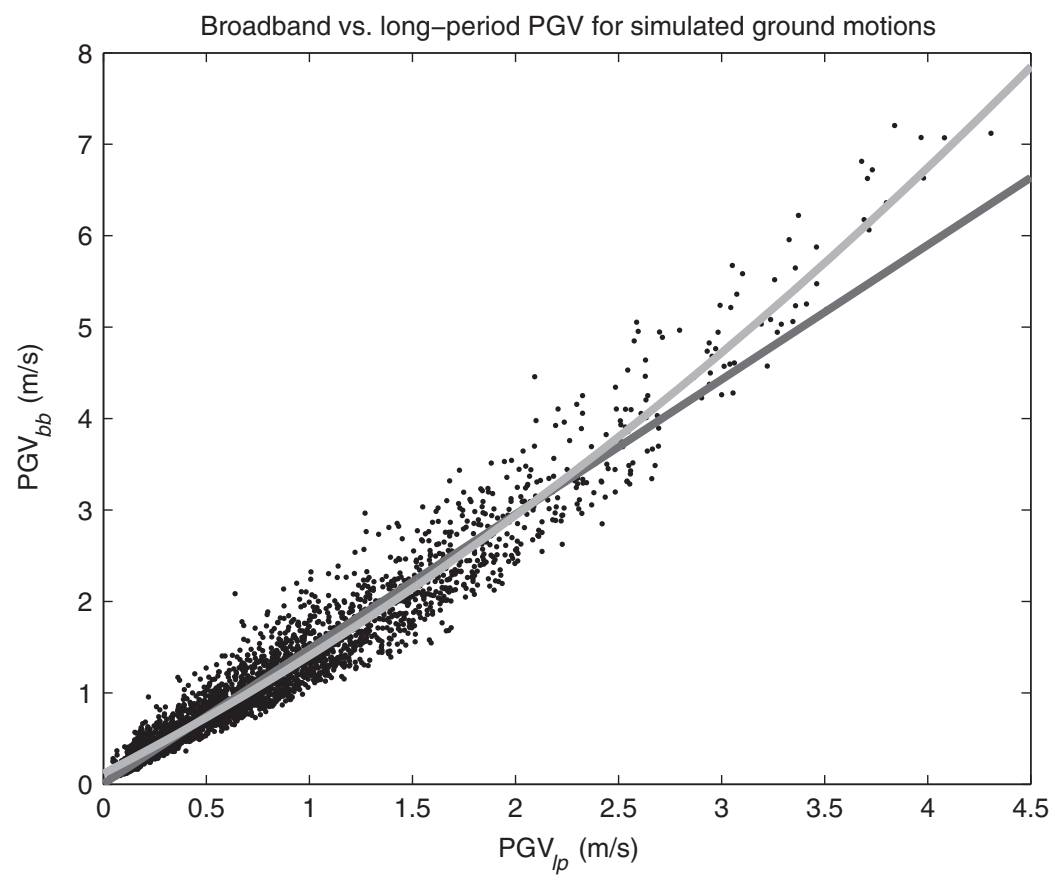

Figure 1. Linear (gray line) and quadratic (light gray curve) relationships between long-period and broadband PGV. We calculate the $P G V_{l p}$ values from low-pass-filtered (2-s corner period) versions of the broadband simulated ground motions from Graves and Somerville (2006). 
0.03 (20 stories)]. Each design meets the proportioning and detailing requirements for beams, columns, and beam-to-column connections in a special moment-resisting frame. Tables 2 and 3 list the values of important design parameters. The welds of each frame are either sound or prone to fracture. Following Hall (1997), we denote a particular building with a three-part code: (1) J for the "Japanese seismic provisions of 1992" or U for the "1994 Uniform Building Code"; (2) the number of stories; and (3) P for "perfect" welds or B for "brittle" welds. Thus, for example, a 20-story building satisfying the 1994 Uniform Building Code seismic provisions with sound welds is coded as U20P.

We now describe the buildings' frames. The six-story buildings have a total height of $98.5 \mathrm{ft}(30.0 \mathrm{~m})$, including one basement. The first story and basement are each $18 \mathrm{ft}(5.49 \mathrm{~m})$ tall, and all other stories are $12.5 \mathrm{ft}(3.81 \mathrm{~m})$ tall. The overall width of the six-story buildings is $120 \mathrm{ft}(36.6 \mathrm{~m})$ and is divided into four bays of equal width. The overall depth of the sixstory buildings is $72.0 \mathrm{ft}(21.9 \mathrm{~m})$ and is divided into three bays of equal width. The 20 -story buildings have a total height of $274 \mathrm{ft}(83.4 \mathrm{~m})$, including one basement. The story and basement heights are the same as those of the six-story building. The overall width of the 20 -story buildings is $100 \mathrm{ft}(30.5 \mathrm{~m})$, and the overall depth is $60.0 \mathrm{ft}(18.3 \mathrm{~m})$. As with the six-story buildings, the width is divided into four bays, and the depth is divided into three bays. Hall (1997) provided schedules for the columns, beams, slabs, and foundations. The exterior frames (and the center three-bay frame of each $\mathrm{J}$ building) have moment-resisting connections; interior frames have simple connections and carry their tributary gravity loads.

We use finite-element models of each building design as detailed in Hall (1997), which also describes the computer program Frame- $2 d$ used for the analyses. Frame- $2 d$ was specifically written to calculate the response of steel moment-frame and braced-frame buildings to large ground motions. Challa and Hall (1994), Hall and Challa (1995), and Hall (1998) validated the special features of Frame-2d, such as joint modeling, nodal updating, and weld fracture, by extensive numerical testing and comparison with experimental data. Also,

Table 2. Values of 1992 Japanese seismic design parameters for the 6- and 20-story building designs

\begin{tabular}{lccccccc}
\hline \hline Model & $Z$ & Soil & $R_{t}$ & $T(\mathrm{~s})$ & $C_{o}$ & $Q / W$ & Drift limit (\%) \\
\hline J6 & 1 & Type 2 & 0.990 & 0.73 & 0.2 & 0.1980 & - \\
J20 & 1 & Type 2 & 0.410 & 2.24 & 0.2 & 0.0820 & 0.50 \\
\hline \hline
\end{tabular}

Source: Reproduced from Hall (1997).

Table 3. Values of 1994 Uniform Building Code seismic design parameters for the 6- and 20 -story building designs

\begin{tabular}{lcccccccc}
\hline \hline Model & $Z$ & $I$ & $R_{W}$ & $S$ & $T(\mathrm{~s})$ & $C$ & $V / W$ & Drift limit (\%) \\
\hline U6 & 0.4 & 1 & 12 & 1.2 & 1.22 & 1.312 & 0.0437 & 0.25 \\
U20 & 0.4 & 1 & 12 & 1.2 & 2.91 & 0.736 & 0.0300 & 0.25 \\
\hline \hline
\end{tabular}

Source: Reproduced from Hall (1997). 
Krishnan (2003) extended Frame-2d into three dimensions and showed that both versions give the same results for a specialized two-dimensional problem.

Although Hall takes advantage of building symmetry by modeling only half of each building, all three-bay moment-resisting or gravity frames are explicitly modeled to the same level of detail. Interior gravity frames contribute realistically to each building's stiffness and strength. The bending strength at a simple beam-to-column connection is modeled by connecting only the web fibers to the joint. The models also fully account for geometric nonlinearities (that is, moment amplification and P-delta): each member has geometric stiffness, and the Frame-2d program updates the positions of end-member nodes. Structurefoundation interaction is modeled with horizontal and vertical springs at the base of each column. The stress-strain relationship of the springs is bilinear and hysteretic; see Hall (1997) for specifications of the springs. We do not, however, believe that this interaction contributes significantly to the behavior of the frame models (Tall Buildings Initiative Guidelines Working Group 2010, sec. 5.3).

Figure 2 shows pushover curves for modified finite-element models of the eight buildings following the procedure described in Hall (1997). We modify the masses assigned to the horizontal degrees of freedom such that the total mass is the seismic design mass and is distributed in proportion to the seismic design loads. Then we apply a horizontal ground

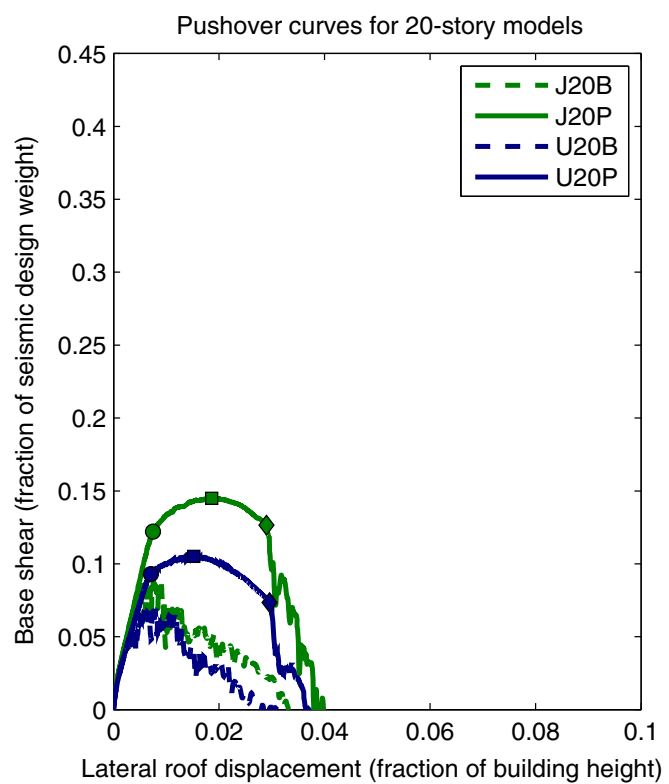

(a)

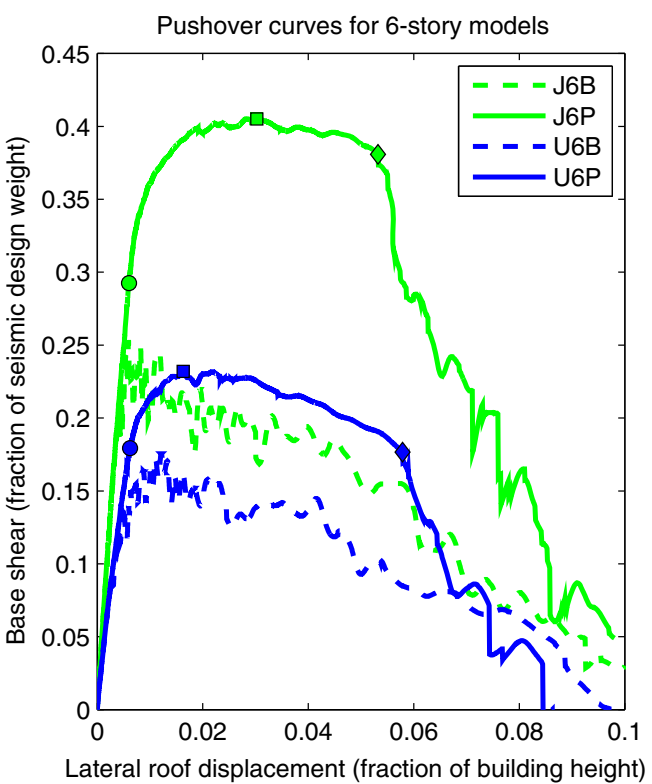

(b)

Figure 2. Pushover curves: (a) the 20-story frame models; (b) the 6-story frame models. The circles, squares, and diamonds indicate the yield, peak, and ultimate points, respectively, for models with sound welds. The ductilities of these models are 3.9 (J20P), 4.2 (U20P), 8.8 (J6P), and 9.3 (U6P). 
acceleration that increases linearly at a rate of $0.3 \mathrm{~g}$ per minute and calculate the frame model's response dynamically. Because the ground acceleration increases slowly, we can use a dynamic analysis procedure to replicate a series of static calculations with the applied lateral forces at each time step proportional to the seismic design forces. As seen in Figure 2 this approach introduces dynamic vibrations in the frame models when the stiffness changes at yielding and especially at weld fracture. This method of pushover analysis allows us to model the strength-degrading part of the curve.

The finite-element models use the fiber method to capture the behavior of beams and columns. The length of each beam or column is subdivided into eight segments, and the cross section of each segment is divided into eight fibers representing the steel wide-flange beam or column; for each beam, two additional fibers represent the concrete slab and the metal deck. Each fiber has a hysteretic, axial stress-strain relationship, including a yield plateau and strain hardening, and each segment has a linear shear stress-strain relation. The end segments of the beams and columns are short to capture the spread of yielding at the plastic hinge zones. The yield strength of steel is greater than the nominal value. Hall and Challa (1995) compared models of steel members using the plastic hinge method or the fiber method to experimental test data. The model using the fiber method (also employed in this study) showed excellent agreement with the experimental results.

The weld fracture model is based on the failures observed after the 1994 Northridge earthquake. In general, these welds proved to be brittle, fracturing prior to local flange buckling. Beam-to-column, column splice, and column baseplate welds are represented by sets of fibers at each weld location. The model randomly assigns an axial fracture strain to each weld according to a user-defined distribution. If the developed tensile strain of a weld fiber exceeds the fracture strain, then the fiber no longer resists tension. For frame models with fractureprone welds, the distribution of axial fracture strain, $\varepsilon_{f}$, normalized by the yield strain, $\varepsilon_{y}$, throughout all welds in the building is as follows: for beam top-flange welds, column splices, and welds at column baseplates, $40 \%$ have $\varepsilon_{f} / \varepsilon_{y}=1,30 \%$ have $\varepsilon_{f} / \varepsilon_{y}=10$, and $30 \%$ have $\varepsilon_{f} / \varepsilon_{y}=100$; for beam bottom-flange welds, $20 \%$ have $\varepsilon_{f} / \varepsilon_{y}=0.7,40 \%$ have $\varepsilon_{f} / \varepsilon_{y}=1$, $20 \%$ have $\varepsilon_{f} / \varepsilon_{y}=10,10 \%$ have $\varepsilon_{f} / \varepsilon_{y}=50$, and $10 \%$ have $\varepsilon_{f} / \varepsilon_{y}=100$ (again, these distributions are denoted B). Hall (1998, sec. 2.4-2.5) defined a different set of fracture strains (denoted F) and found agreement between the model simulations and observations of weld fractures in the Northridge earthquake. Olsen (2008, sec. 2.7.3) compared frame model responses assuming the $\mathrm{B}$ and $\mathrm{F}$ distributions. For the same ground motion, the $\mathrm{B}$ distribution resulted in frame models less likely to "collapse" than did the F distribution, and when the frames did not "collapse," frames with the B distribution tended to have smaller IDRs than those with the F distribution. Thus, the fracture strain distributions used in this paper are less "bad" than those Hall (1998) used to compare with observations of weld fracture in the Northridge earthquake.

Although weld fibers are allowed to fail in tension, welded connections maintain residual bending strength through several mechanisms. First, our distribution of axial fracture strains assumes that beam bottom-flange welds are more susceptible to fracture, consistent with observations after the Northridge earthquake. Thus, in many simulations with weld fractures, only the fibers representing the bottom-flange weld fail, leaving the other fibers intact. Second, a fractured fiber is allowed to resist compression if the fracture gap closes. 
Third, the nodal positions of the beam segments are updated during the simulation, which accounts for axial compression in the beam resulting from flange fracture. This prevents some drop in the bending moment because of the higher force in the flange that is carrying compression. Finally, fibers representing the shear tab cannot fracture.

Special elements model the behaviors of panel zones and basement concrete walls. A panel zone is represented by an element with a nonlinear and hysteretic relationship between moment and shear strain, calibrated with test data (Challa 1992). Also, the panel-zone element has the capability to model doubler plates by increasing the thickness of the panel zone. It occupies a properly dimensioned finite space within the column and connects to beam elements on their edges. Thus the beams have clear-span dimensions. For basement stories, a plane stress element represents the stiffness of concrete walls.

The simulated ground motions have three spatial dimensions, but the finite-element models are two-dimensional frames. To reduce the two horizontal components of a ground motion into one, we define a series of resultants, $r(t ; \theta)$, which combine the east-west, $e(t)$, and north-south, $n(t)$, components:

$$
r(t ; \theta)=e(t) \cos (\theta)+n(t) \sin (\theta)
$$

where $\theta$ ranges from 0 to 179 degrees in 1-degree increments. We then find the angle, $\theta_{v}$, that produces the largest peak-to-peak velocity among all resultant ground motions. The resultant $r\left(t ; \theta=\theta_{v}\right)$ is the horizontal component of ground motion applied in the direction of the building's weak lateral axis. Because damage in this class of buildings can be related to peak-to-peak velocity, we believe that this is the most damaging orientation of the frame model with respect to the ground motion.

We characterize the finite-element model behavior with: a variable representing "standing" or "collapse" as a 0 or 1 , respectively; a variable representing "repairable" or "unrepairable" as a 0 or 1 ; and, if the model is "repairable," a continuous variable representing the interstory drift ratio. We label a frame model response as "collapse" when, as a result of excessive lateral story displacements, the model no longer has the capability to support vertical loads because of P-delta instability. As the model loses its lateral force resistance, its behavior becomes more highly nonlinear, which is expensive to simulate computationally. We seek to identify early that the model has no resistance to lateral forces in order to reduce the computational effort of our simulations. During the calculation of a frame model's response to a ground motion, we terminate the simulation if the peak interstory drift ratio exceeds $20.0 \%$ and deem it a "collapse." If the simulation were allowed to continue to the end of the ground motion, a model with a peak interstory drift ratio above $20.0 \%$ would eventually show a clear dynamic instability as a result of its loss of lateral force resistance. As a check, the largest peak interstory drift ratio of the strongest building-J6P — was $16 \%$ among 3,240 simulations. Thus, we believe that terminating the simulations when the peak interstory drift ratio exceeds $20.0 \%$ does not miscategorize a "standing" model as "collapse."

After finding that a frame remains standing in a simulation, the second concern is whether the lateral force-resisting system of an equivalent existing building would be deemed repairable or be demolished. Iwata et al. (2006) analyzed 12 steel buildings damaged in the 1995 Kobe earthquake and established "repairability limits" for this building class. This study 
defined repairability limits as residual drift over total height (or interstory residual drift) above which a building is not repaired but demolished. It found two types of repairability limits: one based on whether the repair could be physically effected "without any difficult straightening repair construction or large-scale reinforcing construction," and a second limit based on the direct and indirect repair costs to the owner. In the present work, we use the repairability limit based on the physical consideration: if the residual drift ratio over the total height exceeds 1/110, we deem the model "unrepairable." This choice results in fewer unrepairable buildings than if we were to select the limit based on repair costs (that is, a residual drift ratio of $1 / 200)$.

In summary, for each simulated seismic ground motion, we know the intensity of the ground motion (measured as PGD, PGV, $S_{a}$, and $\varepsilon$ ), and we know how eight models of SMF buildings respond to the ground motion excitation (measured as "standing" or "collapse," "repairable" or "unrepairable," and, if "repairable," peak interstory drift ratio). According to our definition, frame models that "collapse" in a ground motion are also "unrepairable."

\section{RESULTS}

By applying ground motions to eight SMF building models, we generate 36 data sets (twelve for each of three building response measures), which inform our proposed regression models to predict building response given an intensity measure value. Here, we plot some of the data sets and describe their important features.

As a short aside, we first address a feature of the vector intensity measures. Figure 3 plots data for the "collapse"/"standing" and "unrepairable"/"repairable" variables for the 20- and 6-story, more flexible frame models with sound welds (U20P and U6P). For the moment, we disregard the information about building response (that is, coloring the points gray, black, or red) and only consider where the vector intensity values lie in their planes. The scalar components of each vector intensity measure are associated, but the reasons for the associations are different. PGD and PGV are associated because seismic ground motions with large PGDs tend to have large PGVs as well, resulting from seismic wave propagation from a fault source to an observing site. $S_{a}$ and $\varepsilon$ are associated because, in the terminology of regression analysis, $\varepsilon$ is the normalized residual of predicting $\log _{e}\left(S_{a}\right)$ from a GMPE; there is no physical relationship between the two in an earth science sense. Any data set constructed from observed values [here, $\log _{e}\left(S_{a}\right)$ ] and the normalized residuals of the observed values from an expectation based on a regression model (here, $\varepsilon$ ) will necessarily have an association [see, for example, Gelman and Hill (2007, sec. 8.2)]. Furthermore, the distinct linear lower bound in the $S_{a}-\varepsilon$ plane results from the limited range of magnitudes (between 6.3 and 7.8) and the source-to-site distances (greater than 0) considered.

Returning to our main argument, we seek to distinguish the region in a plane defined by a vector intensity measure where an SMF would collapse from the region where it would remain standing and, similarly, the region where an SMF would be deemed unrepairable from the region where it would be deemed repairable. A straightforward way to distinguish failure (defined as "collapse" or "unrepairable") from success ("standing" or "repairable") is to locate a line such that $S_{a}$ equals A, a constant (that is, a vertical line in Figures $3 \mathrm{a}$ and $3 \mathrm{~b}$ ), or locate two lines such that PGD equals D and PGV equals V, both constants (that is, a 


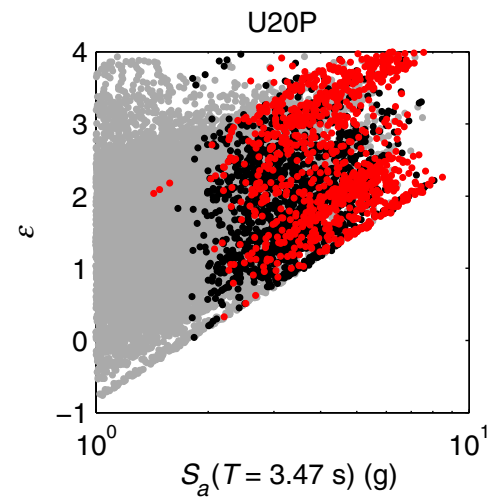

(a)

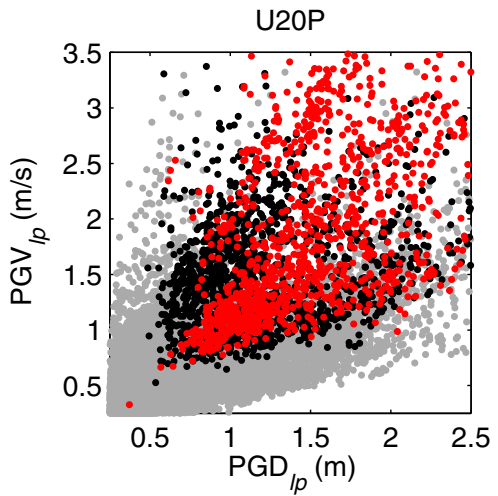

(c)

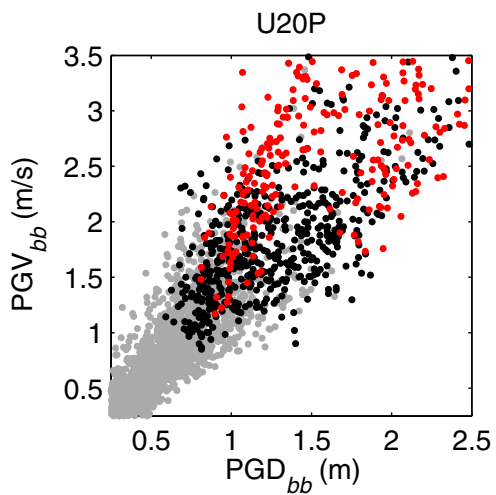

(d)

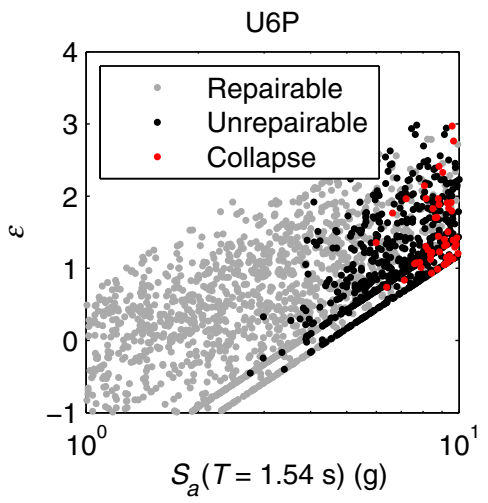

(b) 
vertical line and a horizontal line in Figures $3 \mathrm{c}, 3 \mathrm{~d}$, and 3e). For $S_{a}$ greater than A we would expect the frame model to fail, and for $S_{a}$ less than A we would expect a success. Similarly, for PGD greater than D and PGV greater than V we would expect the frame model to fail, and for all other combinations of PGD and PGV we would expect a success. Specifying these lines provides rules of thumb for the intensity measure values associated with failure of the frame model, but the data for failures overlap the data for successes. Assigning failure or success to disjoint regions of the intensity measure planes miscategorizes many responses.

In the vicinity of such lines distinguishing failure from success, the frame model may or may not fail for the same intensity measure value, depending on the specific ground motion applied to it. We can instead propose regression models for the probability of failure, where the probability is on the interval $(0,1)$, not simply 0 to represent success or 1 to represent failure. Therefore, we now seek a functional form for the regression model to define the probability that a particular frame model will fail given an intensity measure value.

A consideration of the data can suggest appropriate shapes for contours of equal failure probability in the intensity measure plane. In the $S_{a}-\varepsilon$ plane, the building responses seem to depend primarily on the value of $S_{a}$ and possibly secondarily on the value of $\varepsilon$. A contour may be a line where $S_{a}$ is constant, or it may be a curve. In the PGD-PGV plane, the building responses seem to depend on both PGD and PGV. This is clear in the data from simulations using long-period ground motions (Figure 3c) but not in the data from simulations using broadband ground motions (Figures $3 \mathrm{~d}$ and $3 \mathrm{e}$ ). The broadband data cover a much smaller region of the PGD-PGV plane than do the long-period data. Specifically, note the lack of broadband data when PGD is less than $0.7 \mathrm{~m}$ with PGV greater than $1 \mathrm{~m} / \mathrm{s}$ and when PGV is less than $1 \mathrm{~m} / \mathrm{s}$ with PGD greater than $0.5 \mathrm{~m}$. The available broadband data might suggest that contours of equal failure probability are lines of constant PGV. However, if the responses of frame models to broadband ground motions outside the current sample space were available, we might see the same dependence on PGD and PGV rather than PGV alone.

If the contours of equal failure probability should depend on both PGD and PGV, they could be L-shaped, forming right angles, or have acute angles opening on the region with large PGD and large PGV values. The former case is analogous to the initial suggestion that two lines, where PGD equals D and PGV equals V, separate failure of the frame model from success. A simple physical understanding of SMF behavior suggests L-shaped contours. If the PGV is small (say, less than $1 \mathrm{~m} / \mathrm{s}$ ), we would not expect a ground motion with any PGD value to induce collapse. This would be a slow, rigid-body translation of the building over any distance. If the PGD is small (say, less than $0.5 \mathrm{~m}$ ), we would not expect a ground motion with any PGV value to induce collapse. In this case, the ground motion might be too highfrequency to excite significant relative displacement within the frame.

There is, however, a curious feature of the "collapse" and "unrepairable" data as functions of PGD and PGV from simulations using long-period ground motions (for example, Figure $3 \mathrm{c}$ ). This feature complicates the simple description of SMF behavior just offered. The points indicating failure seem to be bounded by a V-, not an L-, shaped curve. This feature is clear in the long-period data but not in the broadband data (compare Figure $3 \mathrm{c}$ to Figures $3 \mathrm{~d}$ and 3e). This V-like shape may be a characteristic of the long-period data and never seen in broadband data. More likely, however, we cannot see it in the broadband data because the 
available data span too limited a region of the PGD-PGV plane. We provide physical explanations for this V-like shape in the Discussion Section.

Also, there is some structure to the long-period collapse data for the 20-story, more flexible frame model (U20P). Imagine three radial lines in Figure 3c, beginning at the origin and continuing approximately through the following points: (PGD $=2 \mathrm{~m}, \mathrm{PGV}=1.5 \mathrm{~m} / \mathrm{s}$ ), $(2,2.5)$, and $(1,2)$. Near the first line, the repairable and unrepairable data are more prominent beneath the collapse data. In contrast, near the second line the collapse data mostly cover the repairable and unrepairable data plotted beneath them. Near the third line, the collapse data are sparse at lower (PGD, PGV) values, revealing many unrepairable data beneath them, and the band of collapse data about the third line seems distinct from the collapse data below it. Although not shown in this paper, the structure just described can also be seen in the data for the 20-story, stiffer frame model (J20P), but this structure is not clear in the data for the equivalent frame models with fracture-prone welds. In those plots, the collapse data almost completely obscure the repairable and unrepairable data beneath them. The structures in the data might indicate regions of the PGD-PGV plane where different collapse mechanisms dominate. They suggest that the probability of failure as a function of PGD and PGV has a more complex dependence on azimuth than any in our proposed regression models. We do not, however, explore these ideas further in this study.

A third interesting feature is the extent to which the "collapse" and "unrepairable" data overlap in the intensity measure planes. The regions of the $S_{a}-\varepsilon$ and PGD-PGV planes where the 20-story, more flexible frame model "collapses" are nearly identical to the regions where the model is "unrepairable." The same cannot be said for the equivalent six-story model, which requires much larger $S_{a}$ values to "collapse" than to be "unrepairable"; in terms of PGD and PGV, the six-story model requires much larger values of both PGD and PGV to "collapse" than to be "unrepairable." We return to this observation in the Discussion Section, where we relate it to each building's global ductility.

\section{REGRESSION MODELS}

There are several steps in finding an appropriate regression model. First, we propose several functional forms to relate a building response variable to an intensity measure variable. For the probabilities of "collapse" and "unrepairable," we propose 30 regression models each, called Models 1-30. Each model includes a transformation of a scalar or vector intensity measure and a function to convert the transformed intensity measure into a probability. We propose ten transformations of PGD, PGV, $S_{a}$, and $\varepsilon$ based on our observations in the previous section. There are three common functional forms that are monotonically increasing on the interval $(0,1)$ : the logistic, hazard, and cumulative normal models (Burnham and Anderson 2002, pp. 195-196). In this study, these functions take a transformed intensity measure value as the argument and produce a probability of failure. Online Appendix A describes the regression models in more detail.

Second, for each response variable we have 12 data sets. Eight represent the responses of the 6 - and 20-story models to the broadband ground motions. The fundamental elastic periods of all frame models are within the energy content of the broadband ground motions. The remaining 4 data sets represent the response of the four 20-story frame models to the long-period ground motions; we do not simulate the responses of the 6-story frame models 
to the long-period ground motions because their fundamental periods are outside the energy content of the simulated ground motions. We find the maximum likelihood estimates of the parameters for each combination of proposed regression model and available data set.

We now determine which of the proposed regression models is best, given the available data and the maximum likelihood parameter estimates, using Akaike's "an information criterion" (AIC) to compare the models. AIC estimates the amount of information lost when replacing the true system (here, a frame model subjected to seismic ground motions) with a model of it (here, our proposed regression models). More precisely, the AIC value for each model estimates this information loss within an additive constant, which is the same for all proposed models. Thus, in practical use the AIC value for a model can only be interpreted relative to another model; it gives no indication of a model's absolute suitability (see, e.g., Burnham and Anderson 2002, sec. 2.2, and references therein for a detailed discussion of AIC). For the four regression models with the smallest AIC values, Tables 4-6 list the AIC value for each of 24 data sets used to model the probability of "collapse" and the probability of "unrepairable." Table 7 lists the same information for regression models of the IDR given that the frame model is "repairable." In addition, these tables list $\Delta_{i}$, which is the difference between the AIC value for regression model $i$ and the minimum AIC value in the set of

Table 4. Comparison of AIC values for the four proposed regression models for "collapse" or "unrepairable" with the smallest AIC values for the 20 -story frame models and longperiod ground motions

\begin{tabular}{|c|c|c|c|c|c|c|c|c|}
\hline \multicolumn{5}{|c|}{ Response: "collapse"/“standing” } & \multicolumn{4}{|c|}{ Response: "unrepairable"/“repairable” } \\
\hline \multicolumn{5}{|c|}{ Energy content: long period } & \multicolumn{4}{|c|}{ Energy content: long period } \\
\hline Building & Model & AIC & $\Delta_{i}$ & Weight & Model & AIC & $\Delta_{i}$ & Weight \\
\hline \multirow[t]{4}{*}{$\mathrm{J} 20 \mathrm{P}$} & 22 & 2,310 & 0 & 1 & 22 & 3,726 & 0 & 1 \\
\hline & 2 & 2,327 & 17.1 & 0 & 2 & 3,752 & 25.7 & 0 \\
\hline & 12 & 2,338 & 28.0 & 0 & 12 & 3,783 & 56.7 & 0 \\
\hline & 30 & 2,433 & 123.1 & 0 & 30 & 3,795 & 68.6 & 0 \\
\hline \multirow[t]{4}{*}{$\mathrm{J} 20 \mathrm{~B}$} & 22 & 7,479 & 0 & 1 & 2 & 9,324 & 0 & 1 \\
\hline & 2 & 7,525 & 46.5 & 0 & 22 & 9,370 & 46.1 & 0 \\
\hline & 12 & 7,669 & 190.0 & 0 & 12 & 9,606 & 282.0 & 0 \\
\hline & 30 & 7,852 & 373.3 & 0 & 9 & 9,802 & 478.0 & 0 \\
\hline \multirow[t]{4}{*}{ U20P } & 22 & 4,265 & 0 & 1 & 22 & 6,349 & 0 & 1 \\
\hline & 2 & 4,295 & 29.5 & 0 & 2 & 6,377 & 28.9 & 0 \\
\hline & 12 & 4,313 & 47.8 & 0 & 12 & 6,506 & 157.5 & 0 \\
\hline & 11 & 4,368 & 102.9 & 0 & 30 & 6,544 & 195.8 & 0 \\
\hline \multirow[t]{4}{*}{ U20B } & 22 & 10,648 & 0 & 1 & 2 & 12,263 & 0 & 0.996 \\
\hline & 2 & 10,689 & 41.0 & 0 & 22 & 12,274 & 10.8 & 0.004 \\
\hline & 12 & 10,905 & 257.4 & 0 & 9 & 12,628 & 364.4 & 0 \\
\hline & 10 & 11,046 & 398.5 & 0 & 29 & 12,654 & 391.1 & 0 \\
\hline
\end{tabular}


Table 5. Comparison of AIC values for the four proposed regression models for "collapse" or "unrepairable" with the smallest AIC values for the six-story frame models and broadband ground motions

\begin{tabular}{|c|c|c|c|c|c|c|c|c|}
\hline \multicolumn{5}{|c|}{ Response: “collapse”/“standing” } & \multicolumn{4}{|c|}{ Response: "unrepairable"/“repairable" } \\
\hline \multicolumn{5}{|c|}{ Energy content: broadband } & \multicolumn{4}{|c|}{ Energy content: broadband } \\
\hline Building & Model & $\mathrm{AIC}$ & $\Delta_{i}$ & Weight & Model & AIC & $\Delta_{i}$ & Weight \\
\hline \multirow[t]{4}{*}{ J6P } & 12 & 325 & 0 & 0.886 & 22 & 1,149 & 0 & 0.919 \\
\hline & 2 & 331 & 6.0 & 0.045 & 2 & 1,154 & 5.3 & 0.066 \\
\hline & 14 & 332 & 7.2 & 0.024 & 24 & 1,158 & 8.9 & 0.011 \\
\hline & 22 & 333 & 7.7 & 0.019 & 29 & 1,161 & 12.1 & 0.002 \\
\hline \multirow[t]{4}{*}{$\mathrm{J} 6 \mathrm{~B}$} & 24 & 558 & 0 & 0.587 & 24 & 1,403 & 0 & 0.559 \\
\hline & 4 & 561 & 3.3 & 0.115 & 22 & 1,404 & 0.6 & 0.417 \\
\hline & 22 & 561 & 3.5 & 0.104 & 4 & 1,411 & 7.5 & 0.013 \\
\hline & 12 & 562 & 4.3 & 0.070 & 2 & 1,411 & 8.0 & 0.010 \\
\hline \multirow[t]{4}{*}{ U6P } & 24 & 629 & 0 & 0.428 & 22 & 1,507 & 0 & 0.558 \\
\hline & 22 & 629 & 0.3 & 0.365 & 24 & 1,507 & 0.5 & 0.426 \\
\hline & 4 & 633 & 3.8 & 0.065 & 29 & 1,515 & 8.1 & 0.010 \\
\hline & 29 & 633 & 3.9 & 0.062 & 2 & 1,517 & 10.2 & 0.003 \\
\hline \multirow[t]{4}{*}{ U6B } & 9 & 863 & 0 & 0.418 & 22 & 1,382 & 0 & 0.749 \\
\hline & 2 & 864 & 0.8 & 0.285 & 2 & 1,386 & 4.0 & 0.100 \\
\hline & 29 & 865 & 1.8 & 0.167 & 29 & 1,386 & 4.3 & 0.086 \\
\hline & 22 & 866 & 2.4 & 0.129 & 24 & 1,387 & 5.6 & 0.045 \\
\hline
\end{tabular}

proposed models. This difference measures how near each proposed model is to the "best" model: when $\Delta_{i}$ is zero, model $i$ is considered the best representation of the available data, and as $\Delta_{i}$ increases, model $i$ is less and less likely to be the "best," given the set of proposed models with their maximum likelihood estimates of the parameter values. These tables also show the weight $w_{i}$ :

$$
w_{i}=\frac{\exp \left(-\frac{\Delta_{i}}{2}\right)}{\sum_{m=1}^{N_{m}} \exp \left(-\frac{\Delta_{m}}{2}\right)}
$$

where $N_{m}$ is the number of models in the proposed set. The weight represents the "weight of evidence" for model $i$ on a scale from 0 to 1 (Burnham and Anderson 2002, p. 75). Each weight can be interpreted as the probability that the associated model is the best among the proposed models given the available data set.

We first consider the regression models ranked in Tables 4-6, predicting the probabilities of "collapse" and of "unrepairable." All of these models use a transformation of the (PGD, PGV) intensity measure, not the spectral-based measures. Further, of the models we propose no single regression model for the probability of "collapse" or the probability of 
Table 6. Comparison of AIC values for the four proposed regression models for "collapse" or "unrepairable" with the smallest AIC values for the 20 -story frame models and broadband motions

\begin{tabular}{|c|c|c|c|c|c|c|c|c|}
\hline \multicolumn{5}{|c|}{ Response: "collapse"/“standing” } & \multicolumn{4}{|c|}{ Response: "unrepairable"/"repairable" } \\
\hline \multicolumn{5}{|c|}{ Energy content: broadband } & \multicolumn{4}{|c|}{ Energy content: broadband } \\
\hline Building & Model & $\mathrm{AIC}$ & $\Delta_{i}$ & Weight & Model & AIC & $\Delta_{i}$ & Weight \\
\hline \multirow[t]{4}{*}{ J20P } & 29 & 633 & 0 & 0.604 & 22 & 940 & 0 & 0.425 \\
\hline & 9 & 633 & 0.9 & 0.378 & 2 & 941 & 0.8 & 0.287 \\
\hline & 24 & 641 & 8.1 & 0.010 & 29 & 941 & 1.2 & 0.228 \\
\hline & 22 & 643 & 10.0 & 0.004 & 9 & 944 & 4.0 & 0.057 \\
\hline \multirow[t]{4}{*}{ J20B } & 29 & 1,255 & 0 & 0.590 & 29 & 1,409 & 0 & 0.491 \\
\hline & 9 & 1,256 & 1.3 & 0.307 & 22 & 1,411 & 1.3 & 0.262 \\
\hline & 19 & 1,258 & 3.5 & 0.103 & 9 & 1,411 & 1.5 & 0.238 \\
\hline & 22 & 1,269 & 14.7 & 0.000 & 2 & 1,417 & 7.9 & 0.010 \\
\hline \multirow[t]{4}{*}{ U20P } & 9 & 825 & 0 & 0.971 & 9 & 1,246 & 0 & 0.548 \\
\hline & 24 & 833 & 8.1 & 0.017 & 22 & 1,247 & 0.9 & 0.350 \\
\hline & 22 & 835 & 10.3 & 0.006 & 2 & 1,250 & 4.0 & 0.073 \\
\hline & 12 & 837 & 11.6 & 0.003 & 29 & 1,251 & 5.9 & 0.029 \\
\hline \multirow[t]{4}{*}{ U20B } & 29 & 1,583 & 0 & 0.741 & 2 & 1,506 & 0 & 0.563 \\
\hline & 22 & 1,586 & 3.8 & 0.112 & 9 & 1,506 & 0.9 & 0.366 \\
\hline & 9 & 1,587 & 4.5 & 0.078 & 22 & 1,510 & 4.5 & 0.059 \\
\hline & 2 & 1,588 & 5.4 & 0.049 & 29 & 1,513 & 7.6 & 0.013 \\
\hline
\end{tabular}

"unrepairable" always has the smallest AIC value. Model 22, however, has the smallest AIC value for a plurality of the data sets (10 of 24), and it is always in the top 4 of the 30 proposed models. These observations suggest two ways to use the model selection results: (1) in future predictions of SMF response, always apply the regression model with the smallest AIC value; (2) for any SMF, use Model 22, even if there is a regression model with a smaller AIC value for that combination of moment frame, energy content of the ground motion, and response variable. Tables B1 and B2 in online Appendix B list the maximum likelihood estimates of the parameter values in Model 22 for the 12 data sets.

As with any empirical model, care should be taken when using the proposed regression models to make predictions. These models in particular warrant mention of a few points. There are no simple ranges of PGD and PGV values to define what would be an extrapolation of the regression models. We can only refer the reader to Figures 3, 4, and 6 to see where the simulation data projects onto the intensity measure planes. The data near its edges can be sparse, and therefore we do not expect that the contours are well constrained for intensity values at the edges of the data. The broadband data are particularly sparse. If frame responses to additional broadband ground motions were available near the edges of or outside the current sample space, the regression model contours could change notably. 


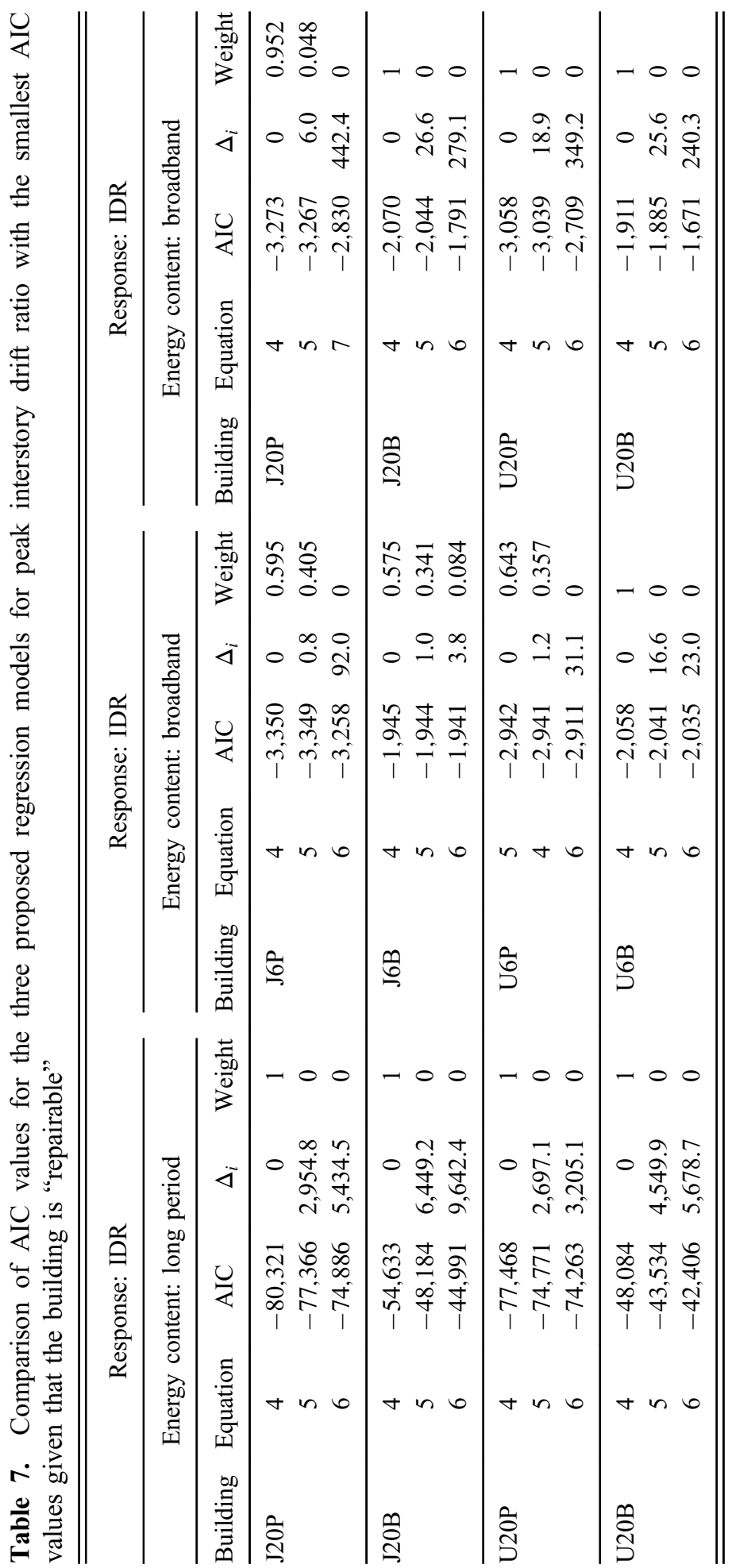


Furthermore, the combination of functional form and estimated parameter values of Model 22 do not provide a physically reasonable extrapolation of the probability of "collapse" or "unrepairable" at extremely large PGD and PGV values. For example, Model 22 would suggest that, as PGD and PGV simultaneously increase, the probability of "unrepairable" decreases for PGDs greater than roughly $3 \mathrm{~m}$ and PGVs greater than roughly $4 \mathrm{~m} / \mathrm{s}$. Thus, although this model most often has the smallest AIC values, it is

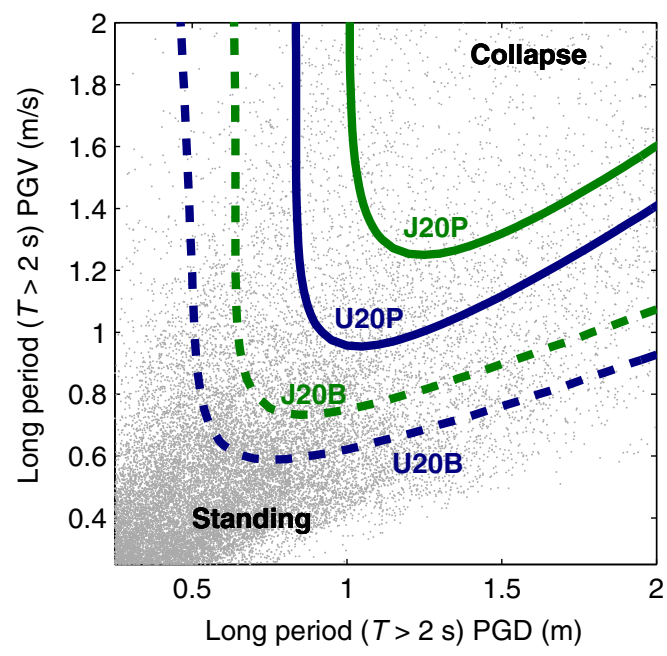

(a)

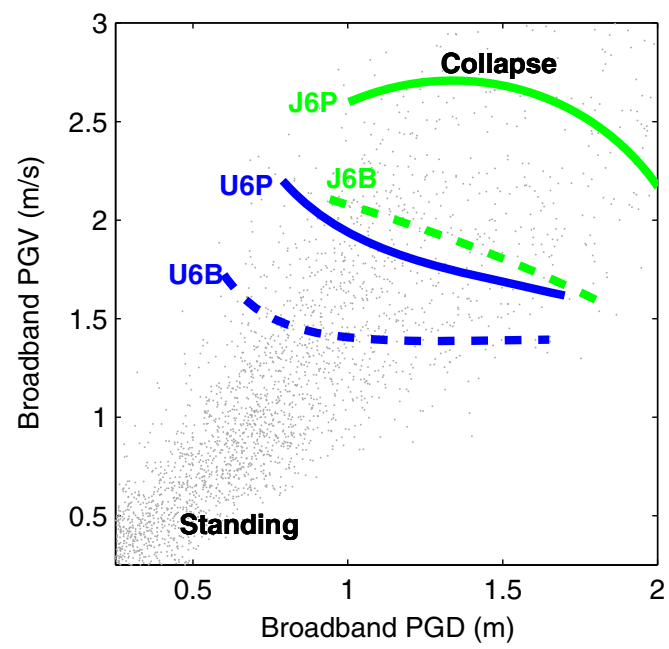

(c)

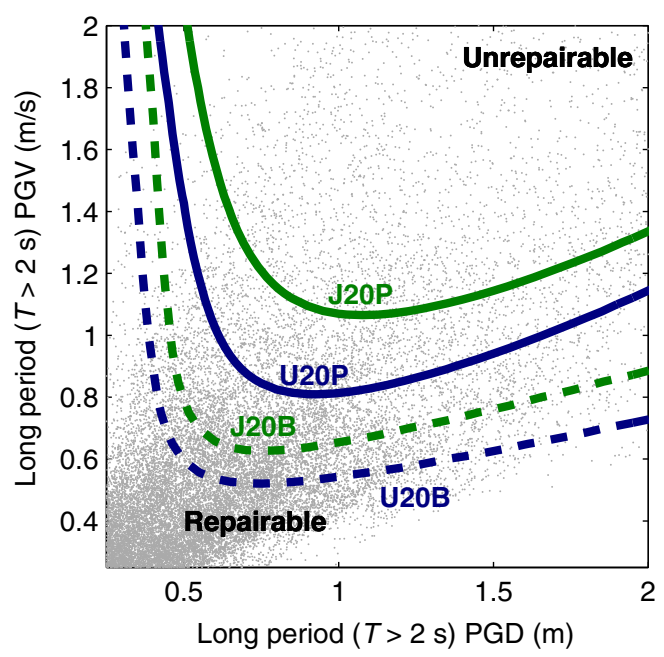

(b)

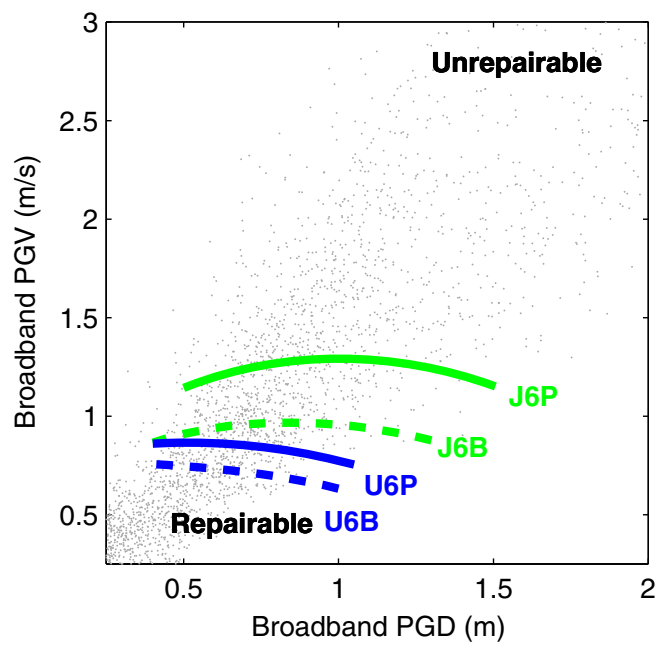

(d)

Figure 4. Contours where the probability of (a) "collapse" or (b) "unrepairable" is $10 \%$ for Model 22 using long-period ground motions and where the probability of (c) "collapse" or (d) "unrepairable" is $10 \%$ for Model 22 using broadband ground motions. The gray points are the PGD and PGV values of the long-period (a), (b) and broadband (c), (d) ground motions. The equivalent $P G V_{b b}$ is approximately $1.5 \cdot P G V_{l p}$ with a standard deviation of $0.24 \mathrm{~m} / \mathrm{s}$. 
not consistent with our expectations of how SMFs behave at extremely large PGD and PGV values. Model 22 is not the best possible relationship to predict the SMF response to a seismic ground motion, but in the region of the PGD-PGV plane where we have data, it is better than all of the other models we proposed.

The results for the selection of a regression model to predict IDR from an intensity measure value, given that the building is "repairable," are much more straightforward. For 23 of the 24 data sets, Equation A4 in online Appendix A has the smallest AIC value of the seven proposed regression models. The functional form of this equation seems consistent with the data, and with its estimated parameter values it is physically reasonable outside the sample spaces of both the long-period and broadband ground motions. Equation A4 uses $\left(S_{a}, \varepsilon\right)$ as a vector intensity measure, which always has a lower AIC value than Equation A6 using $S_{a}$ alone. Also, $\left(S_{a}, \varepsilon\right)$ is a better intensity measure for predicting IDR than the vector (PGD, PGV) or either of its component intensity measures alone. Table B3 in online Appendix B lists the maximum likelihood estimates of the parameter values in Equation A4 for the 12 data sets.

\section{DISCUSSION}

\section{COMPARISONS OF BUILDING RESPONSE BY STIFFNESS AND STRENGTH AND BY WELD STATE}

We can use Model 22 to compare the probabilities of failure for different existing SMFs. Figures 4 and 5 plot the contours of this regression model for all eight frame models where the probability of "collapse" or the probability of "unrepairable" is $10 \%$. Contours at different probabilities are concentric to the one shown for each frame model because of the functional form of Model 22.

Consider Model 22 for the 20-story building responses to the long-period ground motions (Figures $4 \mathrm{a}$ and $4 \mathrm{~b}$ ) and the 6-story building responses to the broadband ground motions (Figures $4 c$ and $4 d$ ). For all values of (PGD, PGV) in our sample spaces, the more flexible, lower-strength frame $(\mathrm{U})$ is more likely to "collapse" or be "unrepairable" than the stiffer, higher-strength frame $(\mathrm{J})$. The models with fracture-prone welds are much more likely to "collapse" or be "unrepairable" than are the equivalent models with sound welds for all intensity measure values. These results are similar to the findings in Hall (1998).

\section{COMPARISONS OF BUILDING RESPONSE BY NUMBER OF STORIES}

The results for Model 22 from the broadband ground motion data sets (Figure 5) allow comparisons between the 6- and 20-story frame model responses. These comparisons, however, are less clear than those between frame models with different stiffness and strength combinations or with different weld states. Specifically, the contours of $10 \%$ failure probability for the otherwise similar 6- and 20-story frame models cross for two of the four "collapse" curves and for three of the four "unrepairable" curves. For example, consider the "collapse" contours for the 6- and 20-story, more flexible frames with sound welds (U6P and $\mathrm{U} 20 \mathrm{P}$ in Figure 5a). The contours cross when $P G D_{b b}=1.41 \mathrm{~m}$ and $P G V_{b b}=1.72 \mathrm{~m} / \mathrm{s}$. Thus, for some (PGD, PGV) values, Model 22 predicts that the 6-story frame is more likely than the 20-story frame to "collapse," and for other (PGD, PGV) values the 20-story frame is more likely to "collapse." The $10 \%$ probability of 


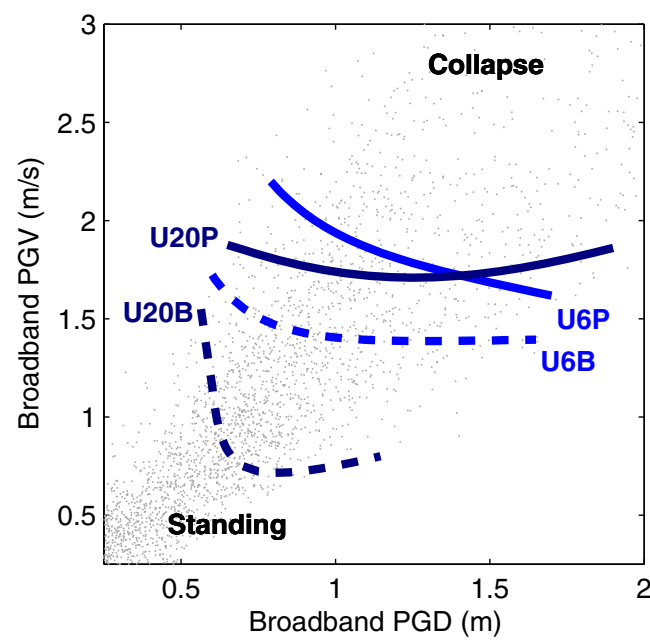

(a)

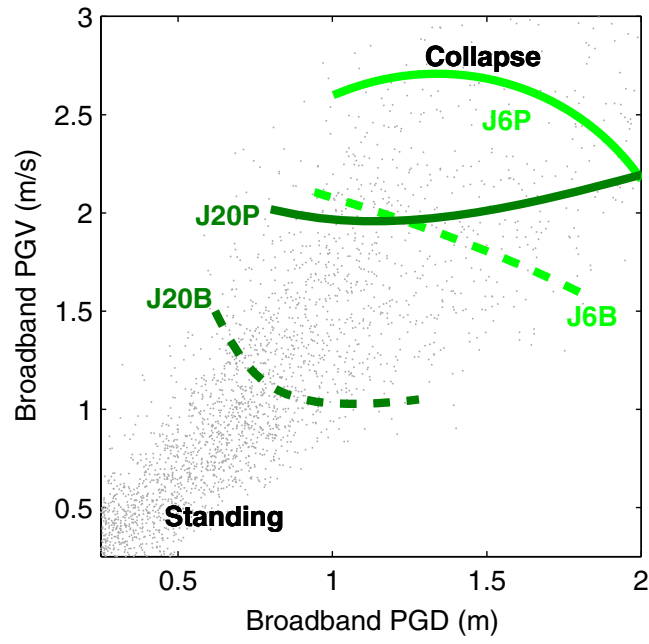

(c)

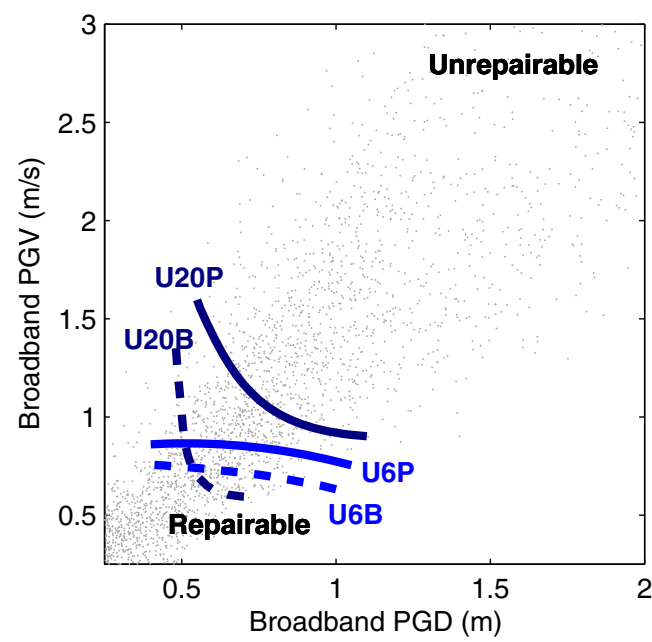

(b)

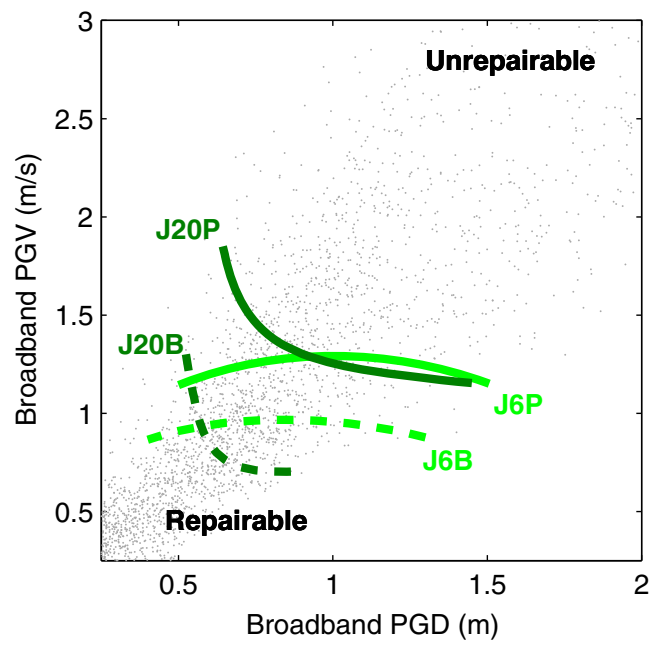

(d)

Figure 5. Contours where the probability of (a) "collapse" or (b) "unrepairable" is $10 \%$ in Model 22 for the more flexible, lower-strength frame (U) and where the probability of (c) "collapse" or (d) "unrepairable" is $10 \%$ in Model 22 for the stiffer, higher-strength frame (J).

"collapse" contours do not cross for any of the frame models with fracture-prone welds: the 6-story frame model is always less likely to "collapse" than is the otherwise similar 20-story model. The $10 \%$ probability of "unrepairable" contours do not cross for the more flexible, lower-strength frames with sound welds: the 6-story frame model (U6P) is always more likely to be "unrepairable" than is the 20-story model (U20P).

The "collapse" contours for the 6-story frames with sound welds and their 20-story equivalents do not cross in a way we might expect. If the contours must cross, we 
would expect a 20-story frame to have a higher "collapse" probability than the otherwise similar 6-story frame in ground motions with longer-period energy content (that is, larger PGD and smaller PGV). A six-story frame should have a higher "collapse" probability in ground motions with shorter-period energy content (larger PGV and smaller PGD). Specifically, the "collapse" contours for the U6P and U20P frame models (Figure 5a) can be more readily explained physically if they were interchanged. The failure probability contours may cross only in this particular data set. Again, these data are from one set of broadband ground motions, and they may be too sparse to constrain the model properly at large (PGD, PGV) values. The data at small (PGD, PGV) values may control the estimated parameter values. Frame responses from another set of broadband ground motions may not show the same crossings of the failure probability contours for 6-story frames and the equivalent 20-story frames.

Figure 6 compares the contours where Equation A4 predicts a peak interstory drift ratio of 0.025 for the eight frames [an IDR of 0.025 is a typical threshold value for the "life safety" performance level in SMFs (ASCE 2000)]. The model selection results indicate that $\varepsilon$ should be included in a predictive model of IDR given an intensity measure value. However, $S_{a}$ seems to dominate such a model, as shown by the nearly vertical contours in Figure 6 . Equation A4 predicts that the stiffer, higher-strength frame model (J) requires a larger $S_{a}$ to induce an IDR of 0.025 than does the equivalent more flexible, lower-strength model (U).

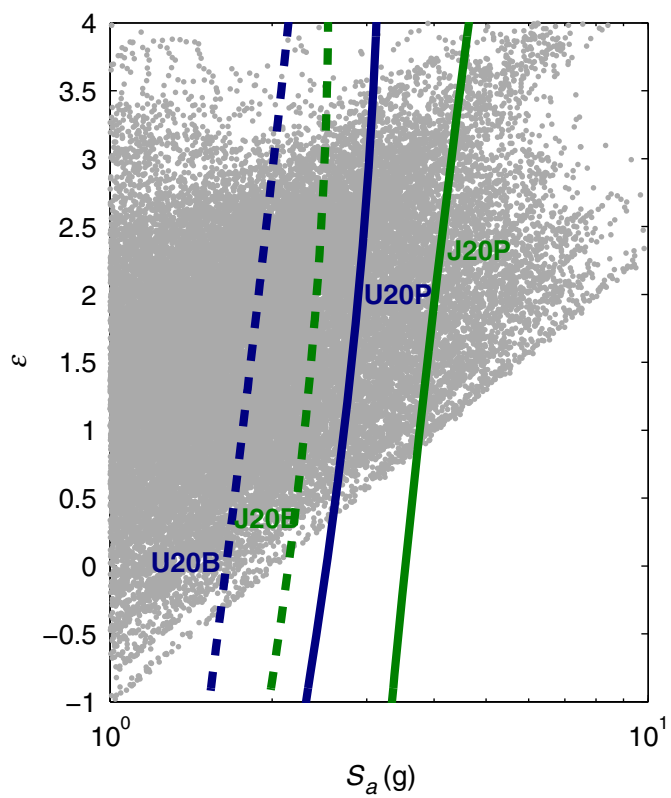

(a)

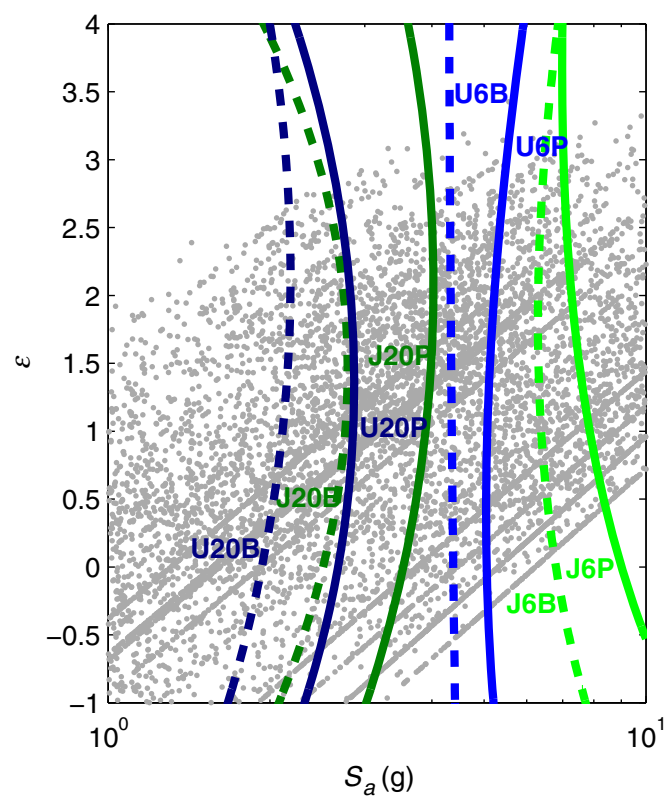

(b)

Figure 6. Contours where the peak interstory drift ratio is 0.025 for (a) the long-period data sets and (b) the broadband data sets. The data points are $\left(S_{a}, \varepsilon\right)$ calculated at the first-mode periods of all frames with sound welds; thus there are two points (a) or four points (b) for each ground motion. These points locate our available data in the $S_{a}-\varepsilon$ plane. 
The equation also predicts that the models with sound welds (P) require a larger $S_{a}$ to cause an IDR of 0.025 than do the equivalent models with fracture-prone welds (B), where we have data available. Comparing the results for our shorter versus taller frame models, Equation A4 indicates that the 6-story models require a larger $S_{a}$ to induce an IDR of 0.025 than the 20 -story models require.

Our comparisons of the 6- versus 20-story building responses contribute to an ongoing discussion of the relative safety of shorter versus taller steel, special moment frame buildings (for example, Naeim and Graves 2005 and Jones and Zareian 2010). Our results suggest that a conclusion either way (that is, taller buildings are safer than shorter buildings or vice versa) may depend on the intensity of the ground motions selected and the metric used to define "safe" (for example, "collapse" versus "unrepairable" versus IDR given that the building is "repairable").

\section{$\left(S_{a}, \varepsilon\right)$ FOR BUILDING RESPONSE PREDICTION}

Baker and Cornell $(2005,2006)$, as well as successive studies, showed that, in the context of ground motion selection and scaling, an accounting of $S_{a}$ and $\varepsilon$ resulted in more precise predictions of building model "collapse" than did an accounting of $S_{a}$ alone. The authors explained that " $[\varepsilon]$ is an indicator of spectral shape" near the spectral period of interest: response spectra with positive $\varepsilon$ values tend to have a "peak" at the spectral period, whereas spectra with negative $\varepsilon$ values tend to have a "valley" (Baker and Cornell 2005, p. 1193; emphasis added). Recall, however, the three quantities required to calculate $\varepsilon$, all at the spectral period of interest: the $S_{a}$ value of the recorded ground motion, the expected $S_{a}$ value from a GMPE, and the error standard deviation in the GMPE. Because none of these contains information about the $S_{a}$ values of the recorded ground motion in the neighborhood of the spectral period, $\varepsilon$ is not a direct measure of the local shape of a response spectrum.

The peaks and valleys that Baker and Cornell described become notable only when ground motion records are selected for target magnitude and source-to-site distance ranges, and are scaled to the same $S_{a}$ value. A ground motion with a negative $\varepsilon$ value is more likely than one with a positive $\varepsilon$ value to induce a large building model response, given that the ground motions have been selected and scaled. In the absence of selection and scaling, however, the additional information that a ground motion has a lower or a higher than expected $S_{a}$ value at a building's fundamental elastic period seems less significant for predicting building response. This explanation is consistent with our finding that regression models with the vector intensity measure (PGD, PGV) predict large building responses better than do models with the vector intensity measure $\left(S_{a}, \varepsilon\right) . S_{a}$ and $\varepsilon$ measure the ground motion at a single period, whereas PGD and PGV contain information over a range of periods, especially those longer than the building model's fundamental elastic period.

\section{GLOBAL DUCTILITY}

In the "Results" section, we noted that the "collapse" data for the 20-story, more flexible frame model with sound welds almost completely overlap the "unrepairable" data in the intensity measure planes, but there is some separation between the "collapse" and "unrepairable" data for the equivalent 6-story model. These observations indicate that once the intensity measure values are large enough to cause the 20 -story frame model to be "unrepairable," 
there is also a possibility that it will "collapse." However, if the intensity measure values are large enough to cause the 6-story frame model to be "unrepairable," they are not necessarily large enough to induce its "collapse." The 20 -story frame model is globally more brittle, and the 6-story model is globally more ductile.

Ductility is a measure of the extent to which a material or structure can accumulate plastic deformation before failure. For a building, the standard quantification of ductility is the ratio of ultimate to yield lateral displacements (e.g., Chopra 2000, secs. 7.2 and 19.1), often measured at the roof to find the global ductility. Figure 2 shows the pushover curves for our eight frame models, and its caption lists the ductilities for the models with sound welds. We do not calculate the ductilities of the frame models with fracture-prone welds because there are no obvious ultimate points. Nonetheless, we can use the observations from the previous paragraph to suggest an alternate way to study the buildings' relative ductilities.

Although we could continue to consider the extent to which the "collapse" data overlap the "unrepairable" data, the curves of $10 \%$ failure probability from our Model 22 provide a more abstract view, less influenced by a few possibly distracting data points. Figure 7 compares the $10 \%$ failure probability curves for the equivalent 6 - versus 20 -story frame models. Roughly speaking, the distance (on a logarithmic scale) between the "unrepairable" and "collapse" curves for a 6-story frame model is greater than the distance between the same curves for the equivalent 20-story model. Thus, the 6-story models are always more ductile than the equivalent 20-story models with either sound or fracture-prone welds, which is consistent with the ductilities from the pushover curves for the models with sound welds. Furthermore, in the more flexible frame model, the presence of fracture-prone welds - a locally brittle component - makes these models globally more brittle. This is especially obvious for the 20-story, more flexible model: the model with fractureprone welds (U20B) has significantly less ductility than the equivalent model with sound welds (U20P). In contrast, the presence of fracture-prone welds in the stiffer frame model does not obviously reduce the global ductility when viewed in this way.

\section{SHAPE OF CURVES SEPARATING "COLLAPSE" FROM "STANDING"}

The regression models we propose have relatively simple functional forms, but there are physical reasons to expect that curves of equal failure probability are more complex. Figure 8 overlays idealized lines and curves on the data for the 20 -story, more flexible frame model with sound welds. Data points indicating collapse are almost exclusively within the region defined by upper and lower "arms."

The upper arm is composed of two lines: one is $P G D_{b b} \approx 0.6 \mathrm{~m}$ when $P G V_{b b}>$ $2 \pi / T(0.6 \mathrm{~m})$, and the other line is $P G V_{b b} \approx 2 \pi / T P G D_{b b}$ for $P G V_{b b}<2 \pi / T(0.6 \mathrm{~m})$ that is, the points corresponding to the elastic resonance of a linear system with period $T=3.47 \mathrm{~s}$. For (PGD, PGV) values to the left of this arm, we expect a corresponding ground motion not to have sufficient displacement at the building's base to possibly induce P-delta instability. In other words, catastrophic failure (i.e., collapse) of the building requires the roof to displace enough to cause P-delta instability. The amplitude of a harmonic shear wave traveling through an isotropic solid (here, an idealized building) doubles on reaching a free surface (here, the building's roof). Thus, we expect that the displacement at a building's 


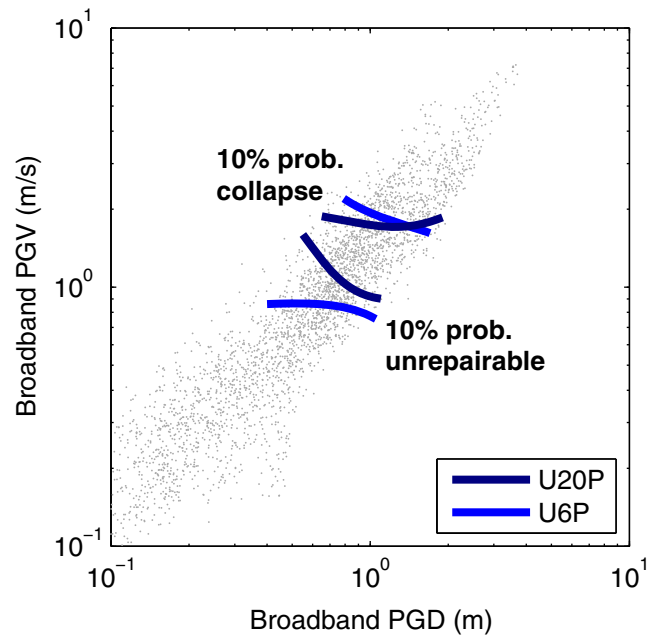

(a)

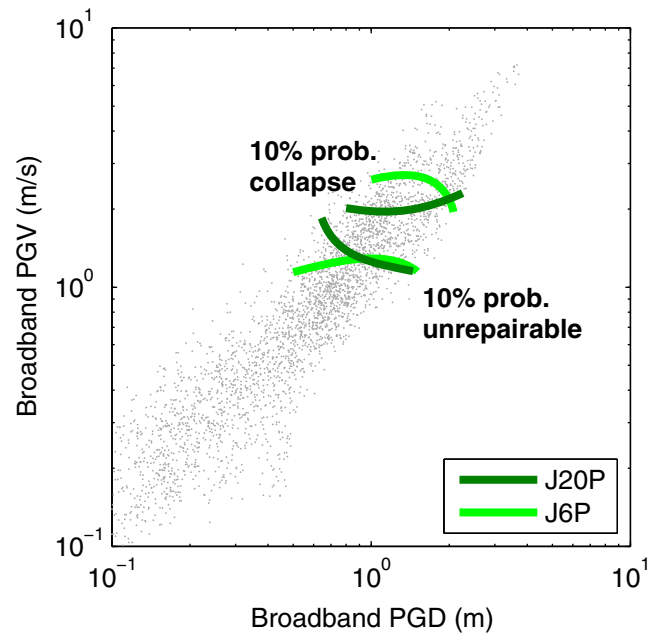

(c)

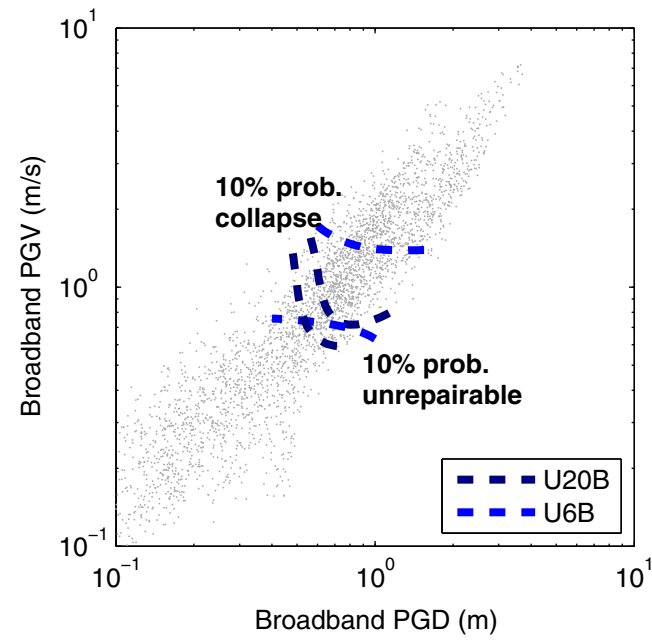

(b)

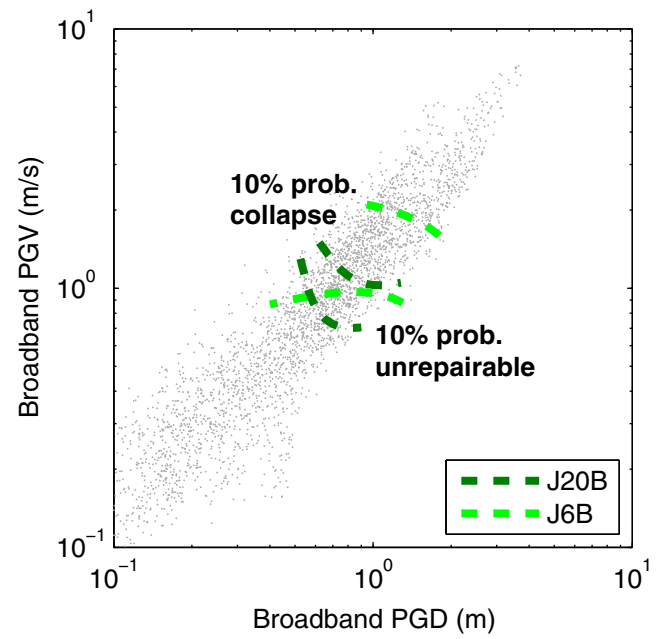

(d)

Figure 7. Comparison of the $10 \%$ failure probability curves. When the $10 \%$ probability of "collapse" curve for a frame model is near its "unrepairable" curve, the frame model is globally more brittle. That is, given a (PGD, PGV) value, the probability of "collapse" is nearly equal to the probability of "unrepairable." When the $10 \%$ probability of failure curves for a frame model are distant, the frame model is globally more ductile; the building is much more likely to be "unrepairable" than to "collapse" for a given (PGD, PGV) value.

base must be at least half of the roof displacement associated with the possibility of P-delta instability. From its pushover curve, the roof displacement of this frame model corresponding to its peak strength is $1.27 \mathrm{~m}$, which corresponds to a peak ground displacement of $0.6 \mathrm{~m}$.

The lower arm is defined as $P G V \propto \sqrt{P G D}$, where $\propto$ represents "is proportional to." Consider a harmonic ground acceleration with period $T$. The ground motion's PGV is 


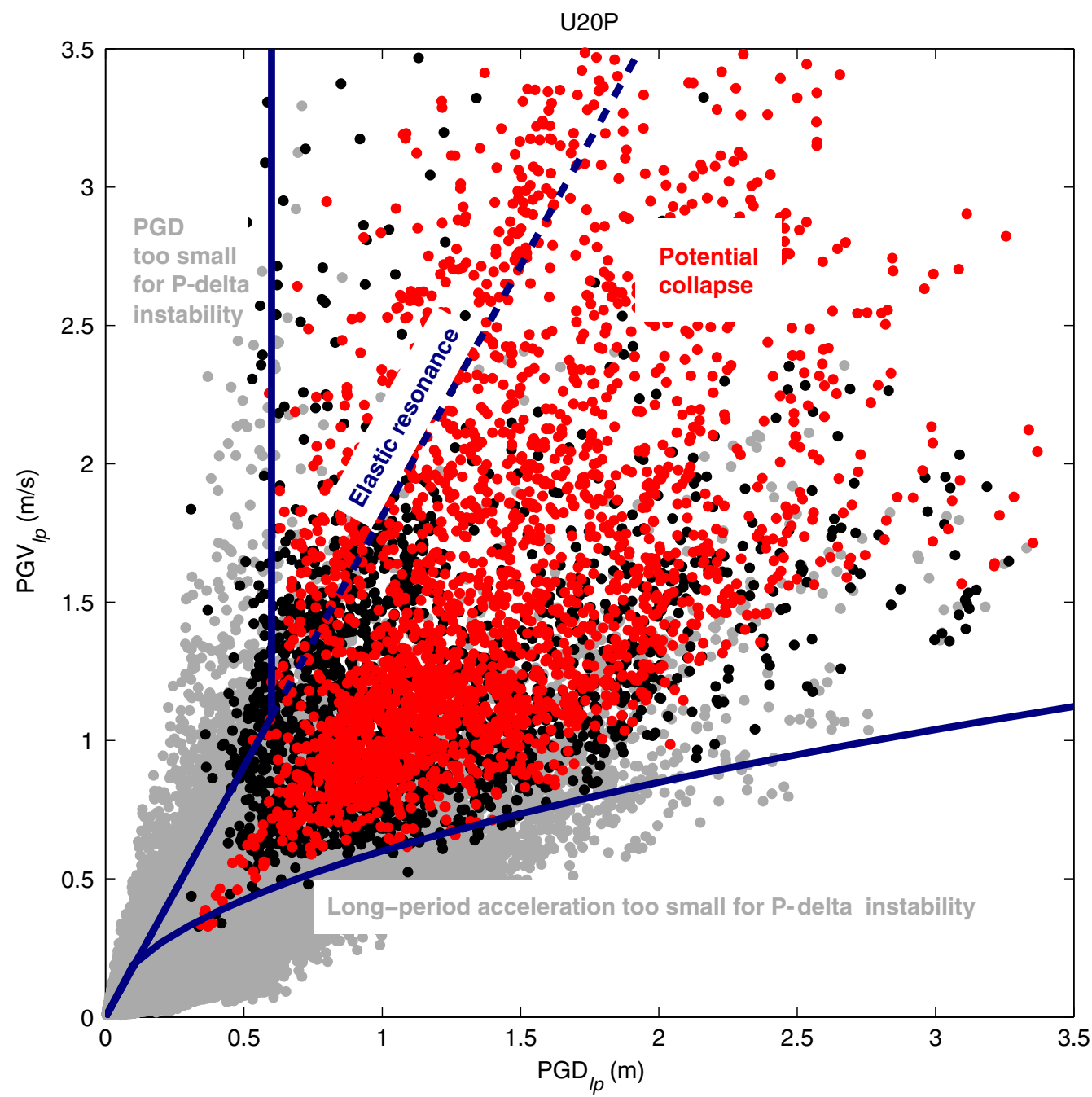

Figure 8. Idealized curves (dark blue) separating regions of the PGD-PGV plane where we would or would not expect "collapse" data points (red) based on a physical understanding of the 20-story, more flexible frame. "Unrepairable" data points are black; "repairable" data points are gray.

$a T / 2 \pi$, and its PGD is $(a T / 2 \pi)^{2}$, where $a$ is the amplitude of the acceleration time history. After equating $T, P G V=\sqrt{a P G D} \propto \sqrt{P G D}$. Song and Heaton (2012) and Song (2014) proposed that there is a possibility of P-delta instability when the product of the building's seismic design mass and the peak acceleration of a ground motion filtered to retain only longperiod energy content exceeds the building's peak base shear from a pushover curve. (Here, this product is $a$, and periods, $T$, greater than the building's fundamental period are "long period.") As the peak ground acceleration increases, the probability of P-delta instability also increases, which is associated with larger (PGD, PGV) values. 


\section{CONCLUSIONS}

When predicting a mid-rise (roughly 5- to 20-story) steel special moment frame response from an intensity measure value of a seismic ground motion, the best choice of intensity measure depends on the building response of interest. For predictions of the probability of "collapse" or the probability of "unrepairable," the vector (PGD, PGV) is a better intensity measure than either of its components alone and better than the vector $\left(S_{a}, \varepsilon\right)$ or its $S_{a}$ component alone. For predicting the peak interstory drift ratio, $\left(S_{a}, \varepsilon\right)$ is the better intensity measure. The peak ground motion measures are better than the spectral-based quantities for predicting large deformations in this type of frame, whereas the spectral-based quantities are better for predicting small to moderate deformations.

The frame model responses to the long-period ground motions show a distinct $\mathrm{V}$ shape where the response transitions from "standing" to "collapse" or from "repairable" to "unrepairable" in the PGD-PGV plane. This V shape suggests a more complicated relationship between intensity measure and frame model response than simply identifying constant PGD and PGV values above which the frame model is expected to "collapse" or be "unrepairable." Although it is not physically realistic at extrapolated intensity values, we prefer Model 22 to predict the probabilities of "collapse" and "unrepairable" for steel special moment frames like those we model. This regression model consistently has the smallest AIC value among the models proposed, and it captures the $\mathrm{V}$ shape feature just described. A better regression model might exist, which simultaneously minimizes AIC, provides a realistic extrapolation, and captures this feature, but we have not yet identified it.

Using our preferred regression model where we have data, the more flexible, lowerstrength frame is always more likely to "collapse" or be "unrepairable" than is the stiffer, higher-strength frame. Unsurprisingly, the frame models with sound welds are significantly less likely to "collapse" or be "unrepairable" than are equivalent models with fracture-prone welds. Such clear statements cannot be made when comparing the 6- and 20 -story frame model responses. In general, the 20-story frame models are more likely to "collapse" than are the otherwise similar 6-story models. A frame model of either height might be more likely to be "unrepairable," depending on the (PGD, PGV) value of the ground motion excitation. This finding may help to explain why different researchers reach different conclusions on the relative safety of shorter versus taller buildings of this class: the conclusion seems to depend on the metric for safety (for example, "unrepairable" versus "collapse") and on the intensity of the ground motion.

\section{ACKNOWLEDGMENTS}

This research was supported by the Southern California Earthquake Center (SCEC). SCEC is funded by NSF Cooperative Agreement EAR-0106924 and USGS Cooperative Agreement 02HQAG0008. The SCEC contribution number for this paper is 1529 . The building response simulations were run at the University of Southern California Center for High Performance Computing and Communications under an agreement with the SCEC Community Modeling Environment project.

We thank Shiyan Song for providing a physical explanation for the V-shaped contours of the probabilities of "collapse" and "unrepairable." Also, we appreciate reviews of or 
comments on this paper by Nicolas Luco, Farzin Zareian, Terrence Paret, and six anonymous reviewers. Their comments greatly improved this paper.

\section{APPENDICES}

Please refer to the online version of this paper to access Appendix A: Proposed Regression Models and Appendix B: Estimated Parameter Values for Model 22 and Equation A4.

\section{REFERENCES}

Aagaard, B. T., Brocher, T. M., Dolenc, D., Dreger, D., Graves, R. W., Harmsen, S., Hartzell, S., Larsen, S., McCandless, K., Nilsson, S., Petersson, N. A., Rodgers, A., Sjögreen, B., and Zoback, M. L., 2008a. Ground-motion modeling of the 1906 San Francisco EarthquakePart II: Ground-motion estimates for the 1906 earthquake and scenario events, Bulletin of the Seismological Society of America 98, 1012-1046.

Aagaard, B. T., Brocher, T. M., Dolenc, D., Dreger, D., Graves, R. W., Harmsen, S., Hartzell, S., Larsen, S., and Zoback, M. L., 2008b. Ground-motion modeling of the 1906 San Francisco Earthquake-Part I: Validation using the 1989 Loma Prieta Earthquake, Bulletin of the Seismological Society of America 98, 989-1011.

American Society of Civil Engineers (ASCE), 2000. Prestandard and Commentary for the Seismic Rehabilitation of Buildings, FEMA 356, Federal Emergency Management Agency, Washington, D.C.

Baker, J. W., and Cornell, C. A., 2005. A vector-valued ground motion intensity measure consisting of spectral acceleration and epsilon, Earthquake Engineering and Structural Dynamics 34, 1193-1217.

Baker, J. W., and Cornell, C. A., 2006. Spectral shape, epsilon and record selection, Earthquake Engineering and Structural Dynamics 35, 1077-1095.

Boore, D. M., and Atkinson, G. M., 2007. Boore-Atkinson NGA Ground Motion Relations for the Geometric Mean Horizontal Component of Peak and Spectral Ground Motion Parameters, Rep. PEER 2007/01, Pacific Earthquake Engineering Research Center, Berkeley, CA.

Burnham, K. P., and Anderson, D. R., 2002. Model Selection and Multimodel Inference: A Practical Information-Theoretic Approach, 2nd edition, Springer, New York, 488 pp.

Challa, V. R. M., 1992. Nonlinear Seismic Behaviour of Steel Planar Moment-Resisting Frames, Ph.D. Thesis, California Institute of Technology, Pasadena.

Challa, V. R. M., and Hall, J. F., 1994. Earthquake collapse analysis of steel frames, Earthquake Engineering and Structural Dynamics 23, 1199-1218.

Chopra, A. K., 2000. Dynamics of Structures: Theory and Applications to Earthquake Engineering, 2nd edition, Prentice Hall, Upper Saddle River, NJ, 844 pp.

Day, S. M., Bielak, J., Dreger, D., Larsen, S., Graves, R., Pitarka, A., and Olsen, K. B., 2005. Lifelines Program Task 1A03: 3D Ground Motion Simulation in Basins, Pacific Earthquake Engineering Research Center, Berkeley, CA.

Gelman, A., and Hill, J., 2007. Data Analysis Using Regression and Multilevel/Hierarchical Models, Cambridge University Press, New York, 625 pp.

Graves, R. W., and Somerville, P. G., 2006. Broadband ground motion simulations for scenario ruptures of the Puente Hills Fault, Paper No. 1052, in Proceedings, Eighth U.S. National Conference on Earthquake Engineering, 18-22 April 2006, San Francisco. 
Hall, J. F., 1997. Seismic Response of Steel Frame Buildings to Near-Source Ground Motions, Rep. EERL 97-05, California Institute of Technology, Pasadena.

Hall, J. F., 1998. Seismic response of steel frame buildings to near-source ground motions, Earthquake Engineering and Structural Dynamics 27, 1445-1464.

Hall, J. F., and Challa, V. R. M., 1995. Beam-column modeling, Journal of Engineering Mechanics 121, 1284-1291.

Iwata, Y., Sugimoto, H., and Kuwamura, H., 2006. Repairability limit of steel structural buildings based on the actual data of the Hyogoken-Nanbu Earthquake, Technical Memorandum of Public Works Research Institute 4022, 86-95.

Jones, P., and Zareian, F., 2010. Relative safety of high-rise and low-rise steel moment-resisting frames in Los Angeles, The Structural Design of Tall and Special Buildings 19, 183-196.

Krishnan, S., 2003. Three-Dimensional Nonlinear Analysis of Tall Irregular Steel Buildings Subject to Strong Ground Motions, Ph.D. Thesis, California Institute of Technology, Pasadena.

Krishnan, S., Ji, C., Komatitsch, D., and Tromp, J., 2006. Performance of two 18-story steel moment-frame buildings in Southern California during two large simulated San Andreas earthquakes, Earthquake Spectra 22, 1035-1061.

Naeim, F., and Graves, R. W., 2005. The case for seismic superiority of well-engineered tall buildings, The Structural Design of Tall and Special Buildings 14, 401-416.

Olsen, A. H., 2008. Steel Moment-Resisting Frame Responses in Simulated Strong Ground Motions: or How I Learned to Stop Worrying and Love the Big One, Ph.D. Thesis, California Institute of Technology, Pasadena.

Reis, E., and Bonowitz, D., 2000. State of the Art Report on Past Performance of Steel MomentFrame Buildings in Earthquakes, Rep. FEMA 355E, SAC Joint Venture.

Song, S., 2014. A New Ground Motion Intensity Measure, Peak Filtered Acceleration (PFA), to Estimate Collapse Vulnerability of Buildings in Earthquakes, Ph.D. Thesis, California Institute of Technology, Pasadena, CA.

Song, S., and Heaton, T. H., 2012. Prediction of collapse from PGV and PGD, in Proceedings of the 15th World Conference on Earthquake Engineering.

Tall Buildings Initiative Guidelines Working Group, 2010. Guidelines for Performance-Based Seismic Design of Tall Buildings, Rep. PEER 2010/05, Pacific Earthquake Engineering Research Center, Berkeley, CA.

(Received 19 January 2012; accepted 9 September 2013) 